\title{
The Formation of Calcium Lactate Crystals is Responsible for Concentrated Acid Whey Thickening
}

\author{
A. Mimouni, ${ }^{\star}$ S. Bouhallab, $†$ M. H. Famelart, $\dagger$ D. Naegele, ${ }^{\star}$ and P. Schuck ${ }^{1}$ \\ *Euroserum, Route de Luxeuil, 70170 Port-sur-Saône, France \\ †UMR 1253 Science et Technologie du Lait et de l'CEuf, INRA-Agrocampus, 35042 Rennes, France
}

\begin{abstract}
The use of spray drying for dehydration of acid whey is generally limited by the appearance of uncontrolled thickening and solidifying of the whey mass during the lactose crystallization step. The origin of this physical change is still unknown and probably linked to complex interactions between physical properties and chemical composition of these products. To understand this phenomenon, we simulated the thickening of concentrated acid whey on a laboratory scale by measuring the flow resistance changes as a function of time and whey composition. The thickening process was characterized by an amplitude of torque and a lag time (induction time). Thickening of lactic acid whey concentrate occurred regardless of the presence of whey proteins or lactose crystals. Moreover, this work clearly demonstrated that the thickening process was due to the formation of filamentous structures corresponding to calcium lactate crystals and showed a large dependence on calcium and lactate contents, $\mathrm{pH}$, and phosphate concentration.
\end{abstract}

Key words: acid whey, rheology, thickening, calcium lactate

\section{INTRODUCTION}

Spray drying is one of the most convenient techniques for producing milk, whey, and derivative powders. However, to maximize energy efficiency, these products must be concentrated at the highest possible TS content during a previous evaporating step, which is usually conducted in falling film vacuum evaporators. Additionally, between the evaporation and drying steps, whey powder manufacturing includes a lactose crystallization step that is often performed in a stirred tank over a few hours (Jensen and Oxlund, 1988). In the case of lactic acid whey powder manufacturing, unpredictable and drastic increases in the viscosity of the concentrate occur during the crystallization step, which prevent the

Received June 27, 2006.

Accepted August 31, 2006.

${ }^{1}$ Corresponding author: Pierre.schuck@rennes.inra.fr concentrate from being pumped to the dryer and often lead to its solidification.

A number of researchers investigated the so-called phenomenon of age-thickening or age-gelation in either concentrated (skim) milk or condensed sweetened milk (Noda et al., 1976; Snoeren et al., 1984; Aoki et al., 2002; Bienvenue et al., 2003). Their results indicated that preheating of milk, storage temperature, and TS content of the concentrate or whey proteins appeared to play an important role in the thickening process. But they mainly indicated that the marked increases in viscosity observed during storage of concentrated (skim) milk and condensed sweetened milk had to be attributed to casein micelle transformation and aggregation. In contrast, to our knowledge, very few studies have analyzed thickening of whey concentrates. Mikelsone (1984) studied the behavior of ammoniated whey concentrate neutralized either by calcium hydroxide or calcium carbonate. He pointed out sharp increases in viscosity before solidification after $90 \mathrm{~min}$ of storage with calcium hydroxide compared with after $45 \mathrm{~min}$ with calcium carbonate. Hargrove et al. (1974, 1976) investigated rheological properties of deproteinized concentrates. They observed that above $60 \%(\mathrm{wt} / \mathrm{wt})$ TS, the concentrates were very viscous and solidified into a firm mass on standing for $30 \mathrm{~min}$ to $1 \mathrm{~h}$. However, no explanation of the phenomenon was proposed.

The purpose of the present study was to understand the causes and origin of lactic acid whey concentrate thickening. In the following, a method was used in which whey concentrates were stirred under controlled conditions (temperature, agitation rate) and changes in rheological properties were measured in real time via the monitoring of flow resistance. Explanations of these changes were then proposed and, finally, the effects of some chemical parameters on thickening of lactic acid whey concentrates were investigated.

\section{MATERIALS AND METHODS}

\section{Preparation of Concentrates}

Preparation of Lactic Acid Whey Concentrate. Lactic acid whey concentrate was prepared by dissolv- 
Table 1. Chemical compositions of lactic acid whey concentrate and deproteinized concentrated acid whey supernatant (DCAWS) prepared at $30^{\circ} \mathrm{C}$

\begin{tabular}{lccccc}
\hline & \multicolumn{2}{c}{$\begin{array}{c}\text { Lactic acid } \\
\text { whey concentrate }\end{array}$} & & \multicolumn{2}{c}{ DCAWS } \\
\cline { 2 - 3 } \cline { 5 - 6 } & $\begin{array}{l}\text { g/kg of } \\
\text { product }\end{array}$ & $\begin{array}{l}\mathrm{g} / 100 \mathrm{~g} \\
\text { of } \mathrm{H}_{2} \mathrm{O}^{1}\end{array}$ & & $\begin{array}{l}\text { g/kg of } \\
\text { product }\end{array}$ & $\begin{array}{c}\mathrm{g} / 100 \mathrm{~g} \\
\text { of } \mathrm{H}_{2} \mathrm{O}\end{array}$ \\
\hline TS & 579.9 & - & & 372.0 & - \\
Total N & 53.3 & 12.7 & & 22.9 & 3.6 \\
NPN & 26.9 & 6.4 & & 22.4 & 3.6 \\
Ash & 73.9 & 17.6 & & 70.5 & 11.2 \\
Lactose & 379.8 & 90.4 & & 184.0 & 29.3 \\
Lactate & 71.2 & 16.9 & & 108.7 & 17.3 \\
Phosphate & 12.5 & 3.0 & & 12.0 & 1.9 \\
Chloride & 10.4 & 2.5 & & 11.8 & 1.9 \\
Sulfate & 1.0 & 0.2 & & 1.1 & 0.2 \\
Calcium & 12.8 & 3.0 & & 10.5 & 1.7 \\
Magnesium & 1.1 & 0.3 & & 1.5 & 0.2 \\
Sodium & 3.1 & 0.7 & & 4.3 & 0.7 \\
Potassium & 13.6 & 3.2 & 22.7 & 3.6 \\
\hline
\end{tabular}

${ }^{1}$ These values were calculated according to the following formula: $\mathrm{g} / 100 \mathrm{~g}$ of $\mathrm{H}_{2} \mathrm{O}=\mathrm{g} / \mathrm{kg}$ of product $/(1,000-\mathrm{TS}) \times 100$.

ing $100 \mathrm{~g}$ of lactic acid whey powder, supplied by Euroserum (Saint Martin Belle Roche, France), in $70 \mathrm{~g}$ of deionized water at room temperature. Complete lactose crystal dissolution was ensured through heating at $80^{\circ} \mathrm{C}$ under agitation for $20 \mathrm{~min}$. Chemical composition of the concentrated lactic acid whey is reported in Table 1. This specific powder to water ratio was set up to mimic the TS content of industrial lactic acid whey concentrates at the end of the vacuum evaporation step.

Preparation of Deproteinized Concentrated Acid Whey Supernatant. The overall steps of the preparative procedure are given in Figure 1. First, whey proteins were removed from industrial acid whey by selective protein concentration with an 8 -kDa ultrafiltration membrane (ceramic membrane, Tami Industries, Nyons, France) as described by Fauquant et al. (1988). Then, the concentration and spray drying of the protein-free permeate were performed at Bionov (Rennes, France) in a 3-stage pilot-plant spray dryer (GEA, Niro Atomizer, St Quentin en Yvelines, France) according to Schuck et al. (2002). Crystallized lactose deproteinized concentrated lactic acid whey was prepared by mixing the above powder $(100 \mathrm{~g})$ with $70 \mathrm{~g}$ of deionized water at 20 or $30^{\circ} \mathrm{C}$ with gentle shaking for 5 min. Centrifugation $\left(160 \times g, 10 \mathrm{~min}, 20\right.$ or $30^{\circ} \mathrm{C}$; Funke Gerber, Berlin, Germany) of this suspension and filtration $(0.45-\mu \mathrm{m}$ syringe filters, Pall Gelman Laboratory, Ann Arbor, MI) of the supernatant resulted in a soluble phase that contained dissolved lactose in slight supersaturation and other soluble components including lactate, phosphate, and calcium in high concentrations (Table 1). This solution, the deproteinized concentrated acid whey supernatant (DCAWS), contained nei-
Lactic acid whey

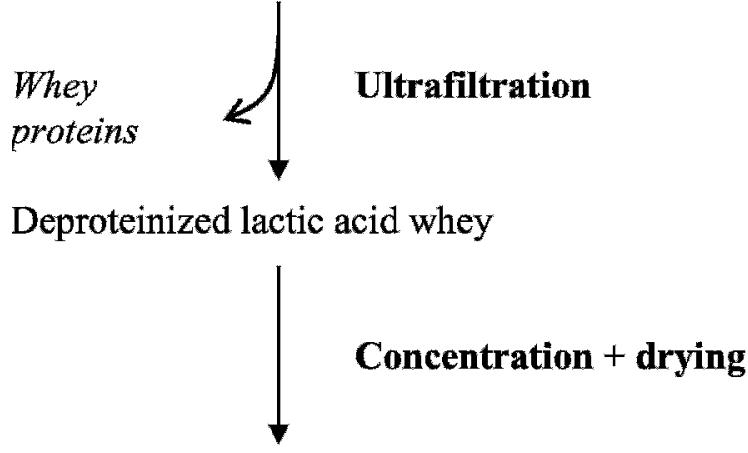

(1)

Powder of deproteinized

Deionized water lactic acid whey

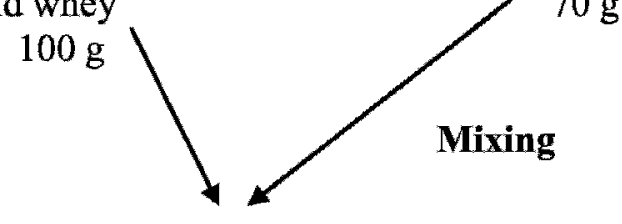

(2)

(3)

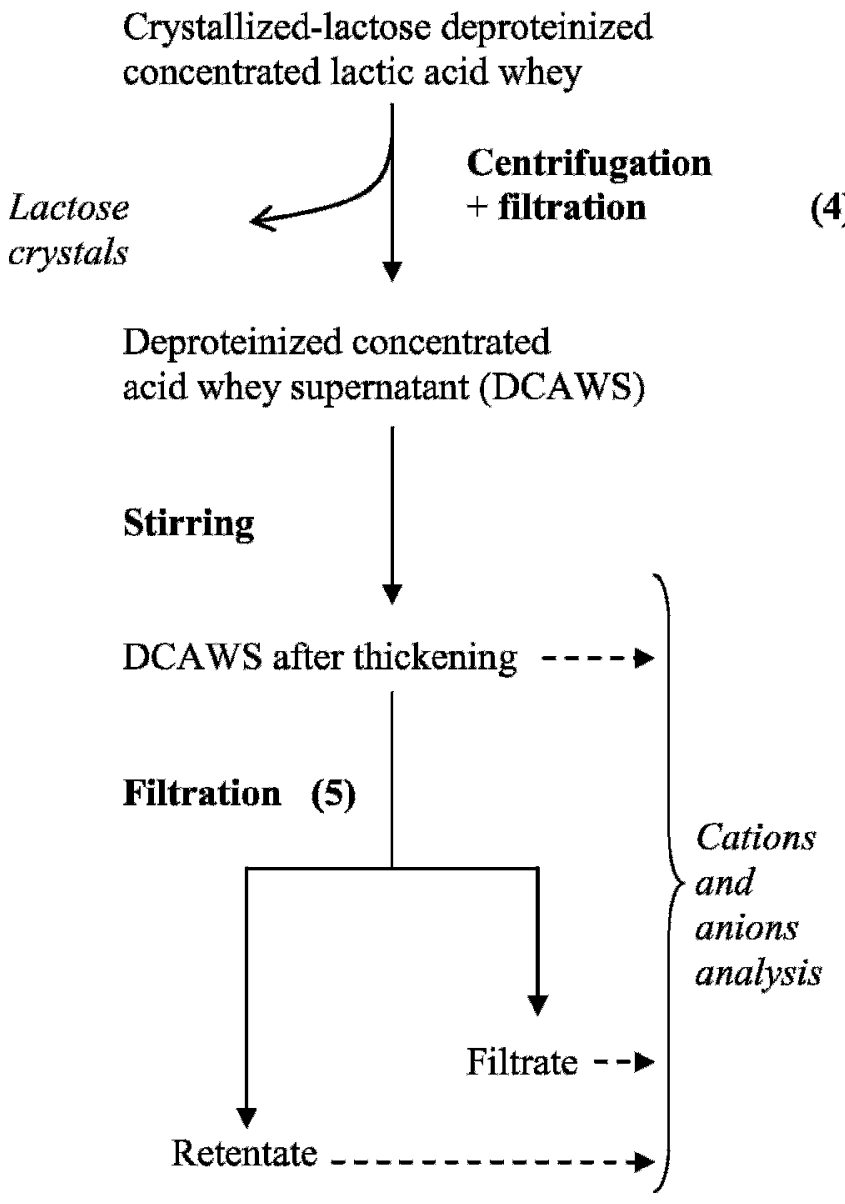

Figure 1. Schematic description of the various steps of the preparation of deproteinized concentrated acid whey supernatant (DCAWS) and the separation of insoluble fraction of thickened DCAWS for cations and anions analysis. 
ther whey proteins nor the undissolved part of lactose and calcium phosphate of the reconstituted suspension. The refractive index value of the DCAWS was 38.5.

Adjustment of $\boldsymbol{p H}$. The $\mathrm{pH}$ of DCAWS ( $\mathrm{pH}=4.1)$ was adjusted to $3.5,3.8,4.6,5.1$, and 6.0 by adding appropriate amounts of concentrated solutions of $\mathrm{NaOH}(50 \% \mathrm{wt} / \mathrm{wt})$ or $\mathrm{HCl}(50 \% \mathrm{wt} / \mathrm{wt})$.

Adjustment of Calcium and Lactate Concentrations. Calcium and lactate concentrations in DCAWS (expressed in $\mathrm{g} / 100 \mathrm{~g}$ of $\mathrm{H}_{2} \mathrm{O}$ ) were adjusted by appropriate dilutions of DCAWS with deionized water, whereas $\mathrm{pH}$ was standardized with $\mathrm{NaOH}(50 \%$ wt/wt) at 5.1 to mimic the $\mathrm{pH}$ of the pure systems described thereafter. This adjustment of calcium and lactate concentration by dilution allowed the calcium:lactate mass ratio to be constant and equal to $1: 10.3$ (Table 1 ).

\section{Preparation of Supersaturated Solutions of Calcium Lactate}

Adjustment of Calcium and Lactate Concentrations in Pure Systems. Supersaturated solutions of calcium lactate at 4 concentrations $(0.86,0.98,1.15$, and $1.34 \mathrm{~g} / 100 \mathrm{~g}$ of $\mathrm{H}_{2} \mathrm{O}$ ), also called pure systems in this paper in contrast with complex systems such as DCAWS, were achieved by adding racemic D/L-sodium lactate syrup (Sigma, Saint Quentin Fallavier, France) to calcium chloride powder (Prolabo, Fontenay sous Bois, France) and deionized water in different proportions. To obtain calcium lactate supersaturation, solutions of calcium chloride and sodium lactate were used instead of adding water to calcium lactate pentahydrate powder. This procedure allows better control of the calcium:lactate mass ratio in model solutions. For each experiment, this ratio was kept at 1:10.3, which is the value of the mass ratio calcium:lactate in DCAWS. The $\mathrm{pH}$ of each solution of calcium lactate was 5.1.

Adjustment of pH and Phosphate Enrichment in Pure Systems. $\mathrm{pH}$ adjustment and phosphate enrichment in pure systems were carried out in supersaturated calcium lactate solutions in which calcium content was kept constant at a concentration of $1.34 \mathrm{~g} /$ $100 \mathrm{~g}$ of $\mathrm{H}_{2} \mathrm{O}$ and calcium:lactate mass ratio at 1:10.3. Phosphate powder $\left(\mathrm{NaH}_{2} \mathrm{PO}_{4} \cdot \mathrm{H}_{2} \mathrm{O}\right.$, Sigma $)$ in appropriate amounts was used in pure systems. For each experiment, the calcium:phosphate mass ratio was kept at 1:1.14 (molar ratio 1:0.5; i.e., the same mass ratio as in DCAWS). The $\mathrm{pH}$ of pure systems enriched or not with phosphate was adjusted to 3.5, 5.1, and 6.1 by adding appropriate amounts of concentrated solutions of $\mathrm{NaOH}(50 \%$ wt/wt) and $\mathrm{HCl}(50 \% \mathrm{wt} / \mathrm{wt})$.

\section{Chemical and Physical Characterization of the Concentrates}

Chemical Analysis. The chemical compositions of lactic acid whey concentrate and DCAWS are reported in Table 1 . The water content was determined by weight loss after drying $5 \mathrm{~g}$ of samples at $105^{\circ} \mathrm{C}$ for $7 \mathrm{~h}$. Total $\mathrm{N}$ and $12 \%$ TCA-soluble nitrogen (NPN) were determined by Kjeldahl method using a conversion factor of 6.38. Lactose was determined by enzymatic method using a lactose/D-galactose kit (R-Biopharm, Saint Didier au Mont d'Or, France). Ash was measured after incineration at $550^{\circ} \mathrm{C}$ for $5 \mathrm{~h}$. Lactate, phosphate, chloride, and sulfate contents were determined by ion chromatography (Gaucheron et al., 1996). Calcium, magnesium, sodium, and potassium contents were determined by atomic absorption spectrometry as reported by Brule et al. (1974).

Monitoring Lactose Crystallization in Lactic Acid Whey Concentrate by Refractometry. When lactose crystallization occurs in whey concentrates during batch experiments, TS content decreases with decreasing lactose content in the soluble phase. Furthermore, Schuck et al. (2005) reported a linear relationship between TS content in the soluble phase of whey concentrates and refractive index (RI) expressed in ${ }^{\circ}$ Brix. Therefore, as well as in pure lactose solution (Mimouni et al., 2005), lactose crystallization kinetics in lactic acid whey concentrate was followed by monitoring the $\mathrm{RI}$ as a function of time, using a handheld Atago refractometer (Atago, Tokyo, Japan).

Microscopy. The DCAWS was observed via phase contrast optical microscopy (Olympus BX 51, Olympus France, Rungis, France) without previous specific preparation of the sample.

\section{Stirring Procedure}

Samples of concentrates or pure systems $(25 \mathrm{~mL})$ were introduced into the filling cylinder of an AR 2000 rheometer (diameter $=30 \mathrm{~mm}$; TA Instrument France, Guyancourt, France) and equilibrated at working temperature for $2 \mathrm{~min}$. Stirring then started at time $\mathrm{t}=0$ using a standard size vaned rotor (4 rectangular blades, right-angle between blades, height $=42 \mathrm{~mm}$, diameter $=$ $28 \mathrm{~mm}$, bottom gap $=10 \mathrm{~mm}$; TA Instrument France) and performed at steady angular velocity (120 rad/s). The continuous stirring mode was preferred to lower the duration of the experiment and to mimic industrial conditions. Stirring was carried out at constant temperature using a Peltier temperature control system. Stirring runs were performed either at 30 or $20^{\circ} \mathrm{C}$. Two replicates were conducted for each experimental run. 


\section{Flow Resistance Monitoring}

In this study, the flow resistance of suspensions and solutions was defined as the torque value (expressed in $\mathrm{N} \cdot \mathrm{m}$ ) automatically enforced to keep constant the angular velocity of the rotor. Torque was monitored as a function of time. Thickening was considered to start when the slope of the curve torque vs. time exceeded 5 $\mu \mathrm{N} \cdot \mathrm{m} / \mathrm{min}$. The gap of time between the beginning of stirring and the beginning of thickening was called induction time. Thickening was also characterized by the amplitude $\Delta F, 10^{-4} \mathrm{~N} \cdot \mathrm{m}$ ) of torque, which was defined as the difference between maximum and minimum of the curve torque vs. time.

\section{Separation of the Insoluble Fraction of DCAWS and Chemical Analysis}

Samples of DCAWS (4.5 g) were collected 60 min after induction time and introduced into a Vivaspin tube (100-kDa cut-off; Vivascience AG, Hannover, Germany) for centrifugal filtration (step 5 in Figure 1) at 3,900 $\times g$ for $2 \mathrm{~h}$ (Firlabo, Meyzieu, France). Cationic and anionic concentrations (wt/wt) were determined in the initial sample of DCAWS, in the filtrate, and in the retentate of centrifugal filtration of DCAWS. For easier interpretation, each cationic and anionic concentration in filtrate and retentate is expressed as a percentage of the respective cationic and anionic concentrations in DCAWS. Analyte masses were calculated from experimental values of analyte concentrations and mass of DCAWS sample, retentate, and filtrate. These calculations ascertained that mass balance was complete.

\section{RESULTS AND DISCUSSION}

\section{Observation of Thickening}

Flow Resistance Changes in Lactic Acid Whey Concentrate. In the course of stirring, performed at constant temperature $\left(30^{\circ} \mathrm{C}\right)$ and constant rate $(120$ $\mathrm{rad} / \mathrm{s}$ ), the torque, which measured the flow resistance of lactic acid whey concentrate, underwent an evolution including 4 steps (Figure 2a). During the first step (from $\mathrm{t}=0$ to $30 \mathrm{~min}$ ), torque decreased. During the second step (from $t=30$ to $125 \mathrm{~min}$ ), torque remained approximately constant. The third step (from $t=125$ to 275 min) was characterized by a sharp increase in torque, followed by a final decreasing step. At the same time, a decrease in the refractive index of the concentrate from $t=0$ was observed, indicating an increase (exponential decay-type) of lactose crystal content in the suspension, as already observed during lactose isothermal crystallization from pure supersaturated solution (Mimouni et al., 2005).

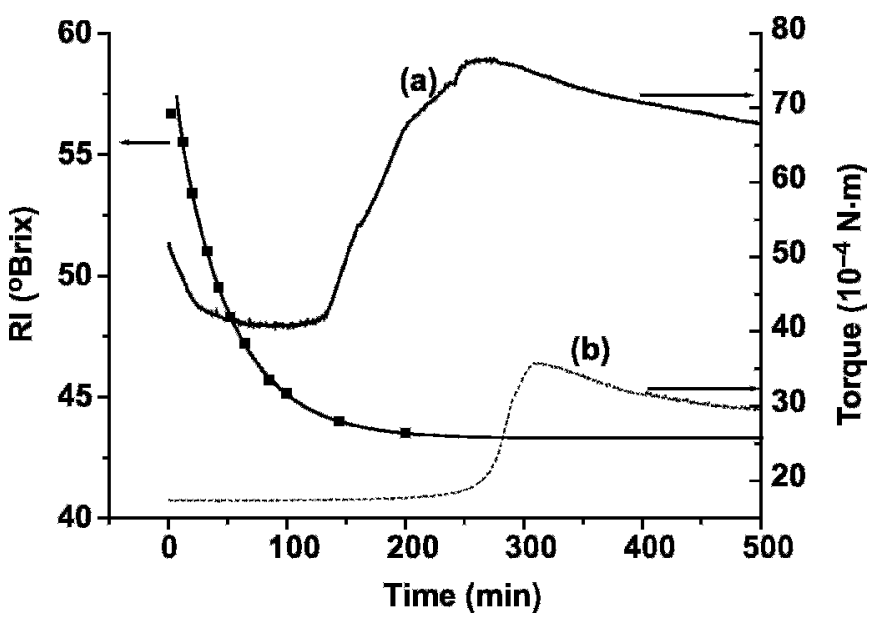

Figure 2. Evolution of torque $\left(10^{-4} \mathrm{~N} \cdot \mathrm{m}\right)$ at $120 \mathrm{rad} / \mathrm{s}$ as a function of time (min) during stirring of lactic acid whey concentrate (a) and deproteinized concentrated acid whey supernatant (DCAWS) $\left(----;\right.$ b) at $30^{\circ} \mathrm{C}$. Evolution of refractive index (RI, ${ }^{\circ}$ Brix) of the soluble phase of lactic acid whey concentrate during stirring at $30^{\circ} \mathrm{C}$ is shown (- - $)$ ) as a function of time (square = experimental data; line = exponential decay best fit).

Flow Resistance Changes in DCAWS. Considering flow resistance of DCAWS as a function of time during stirring $\left(30^{\circ} \mathrm{C}, 120 \mathrm{rad} / \mathrm{s}\right)$, only 3 steps were observed (Figure 2b). In contrast to whey concentrate, the first decreasing step was not detected. From $t=250$ min, a sharp increase in torque was observed, followed by a final decrease. At the same time, refractive index remained approximately constant (results not shown) and optical microscopy did not exhibit tomahawk-habitus crystals of $\alpha$-lactose monohydrate in DCAWS, showing that no lactose crystallization occurred in that solution. Buma (1980) reported that the viscosity of lactose solutions strongly depends on lactose concentration. Additionally, in the course of stirring, DCAWS exhibited neither lactose crystallization nor the first stage of torque decrease (Figure 2b). Therefore, it appears evident that the first step of torque decrease of lactic acid whey concentrate was due to lactose crystallization. The increasing amount of lactose crystals could reasonably explain the second step characterized by constant torque. As also reported by Buma (1980), the presence of crystalline lactose increased the viscosity of whey concentrate and may counterbalance the decrease of lactose concentration in the soluble phase. More generally, the dynamic viscosity of dilute particle suspensions varied with solids volume fraction for given particle size and shape (Petrie, 1999; Pabst et al., 2006).

Considering the sharp increase in flow resistance of lactic acid whey concentrate (third step) and DCAWS (second step), it is notable that this step was observed 

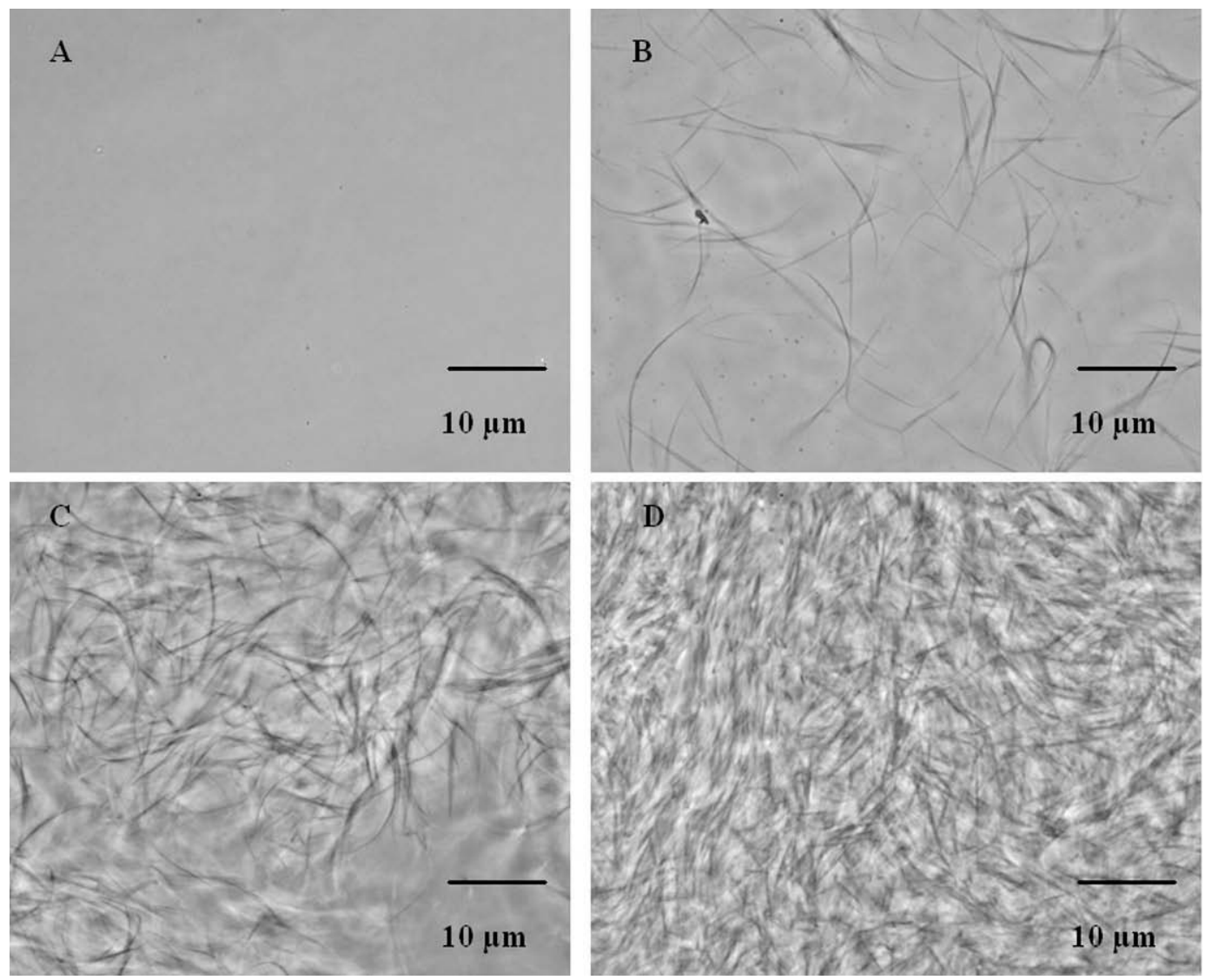

Figure 3. Phase contrast optical micrographs of deproteinized concentrated acid whey supernatant $($ DCAWS $)$ sampled at $t=0(A), t=$ $260 \mathrm{~min}(\mathrm{~B}), \mathrm{t}=275 \mathrm{~min}(\mathrm{C})$, and $\mathrm{t}=290 \mathrm{~min}(\mathrm{D})$ during stirring run at $120 \mathrm{rad} / \mathrm{s}$ and $30^{\circ} \mathrm{C}$.

to occur both in the presence and in the absence of protein and lactose crystals.

Moreover, thickening was already observed in deproteinized whey concentrate (Hargrove et al., 1974, 1976). Therefore, these results clearly showed that neither protein nor lactose crystals were directly responsible for this typical increase in flow resistance.

\section{Origin of Thickening}

Formation of Filament-Like Particles. During stirring at $120 \mathrm{rad} / \mathrm{s}$ and $30^{\circ} \mathrm{C}$ (Figure 2b), DCAWS was collected at different times and analyzed by phase contrast optical microscopy. Micrographs are shown in Figure 3 . At $t=0$, DCAWS was a pure solution without any apparent solid structure. The same was observed at $\mathrm{t}=230 \mathrm{~min}$ (result not shown), indicating that no change had occurred during this period. At $t=260$ min, filament-like structures of about $10 \mu \mathrm{m}$ long were detected. The number of these filaments further increased as a function of time and, at $t=290 \mathrm{~min}$, dense entanglement of filaments was observed in the whole sample.
Taking Figure 2b and Figure 3 together, it can be noticed that the thickening and the appearance of numerous filament-like structures in DCAWS were simultaneous events. Additionally, it is well established that, for a given solid volume fraction, the viscosity of a particle suspension varies strongly and positively with the aspect ratio (i.e., elongation) of the particles (Pabst et al., 2006). Application of this property leads (for example, in ceramic processing) to the use of needle-like particles in suspension to achieve, with relatively low solids fractions, high viscosities that exceed the usual viscosities encountered with isometric particles. Additionally, fiber particles are used to reinforce thermoplastics (Ausias et al., 2006). For these reasons, it can be proposed that the drastic increase in flow resistance of whey concentrates (Figure 2) was induced by the formation of these filament-like structures. As the filaments lengthened and their number increased, the flow resistance of the suspension was likely to increase. High shear rate is known to change some of the physical properties of the elongated particle suspension, such as spatial orientation of the particles in the direction of 

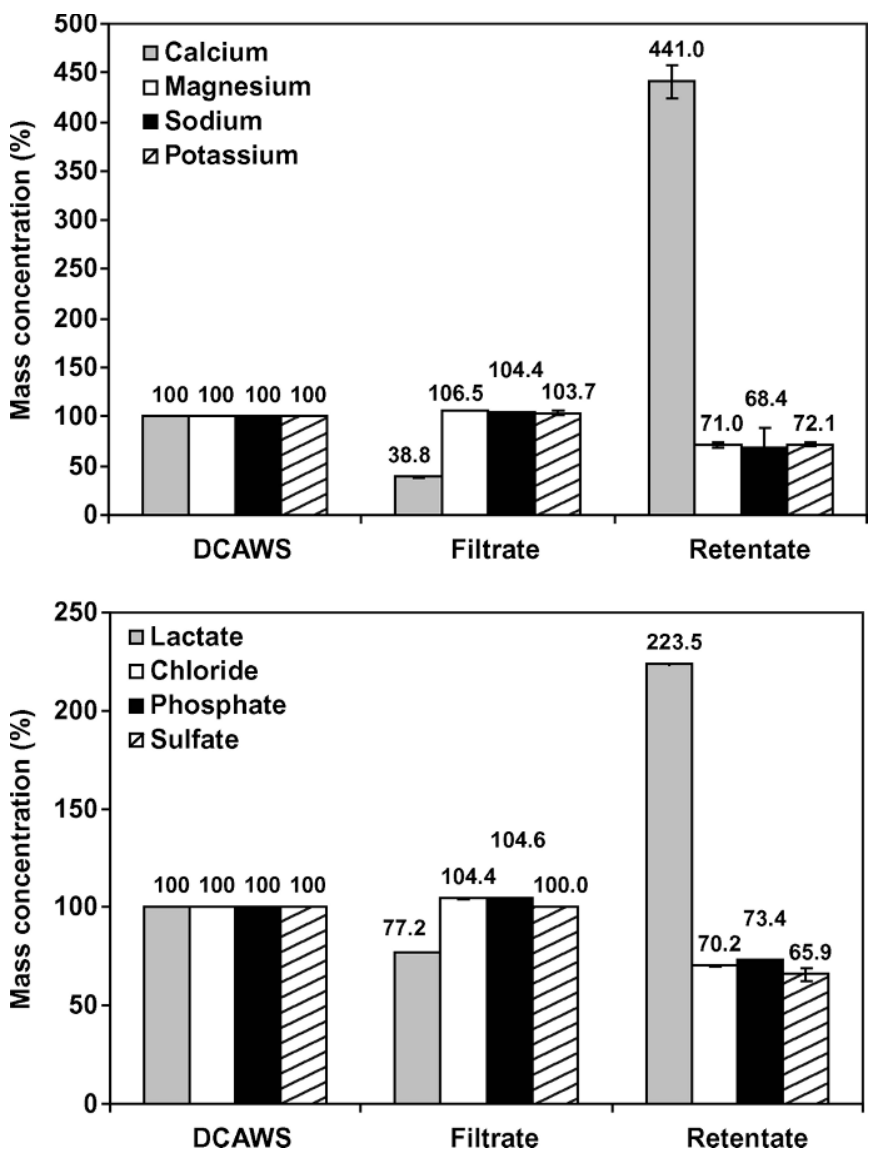

Figure 4. Cationic and anionic mass concentrations in deproteinized concentrated acid whey supernatant (DCAWS) 60 min after induction time, and in the filtrate and retentate of centrifugal filtration of DCAWS. Concentrations are expressed as percentage of the respective cationic and anionic mass concentrations in DCAWS.

the shear flow (Fan et al., 1998; Marti et al., 2005). Some of these changes result in a decrease in viscosity of the suspension when the amount of filament particles no longer increased, resulting in the final torque decrease shown in Figure 2.

Identification of Calcium Lactate Crystals. A chemical analysis was performed to determine the chemical nature of formed filaments. The results reported in Figure 4 clearly showed that lactate and calcium were the only species to be more concentrated in the retentate of centrifugal filtration of DCAWS than in the whole DCAWS. It is, therefore, reasonable to assume that the insoluble filament-like structures are crystals of calcium lactate.

Other observations supported this assumption. Firstly, crystallization of calcium lactate pentahydrate from supersaturated aqueous solution yields needlelike crystals as those observed during thickening of DCAWS (results not shown). Secondly, needle-shaped calcium lactate pentahydrate crystals were also re-

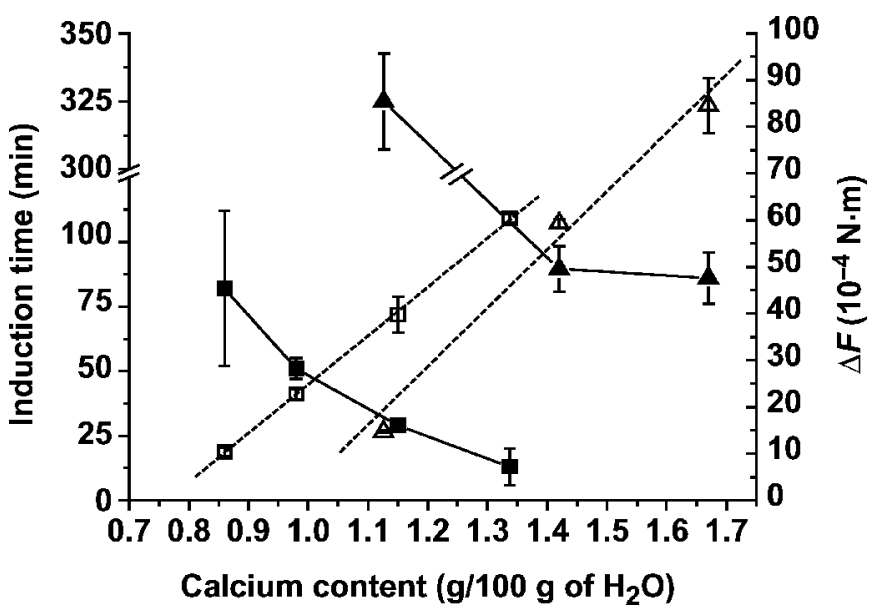

Figure 5. Induction time (min, solid symbols) and respective torque amplitude $\left(\Delta F, 10^{-4} \mathrm{~N} \cdot \mathrm{m}\right.$, open symbols), as a function of calcium concentration $\left(\mathrm{g} / 100 \mathrm{~g}\right.$ of $\left.\mathrm{H}_{2} \mathrm{O}\right)$ at constant calcium:lactate mass ratio of $1: 10.3$ during stirring runs $\left(120 \mathrm{rad} / \mathrm{s}, 20^{\circ} \mathrm{C}\right)$ of pure systems $(\square, \square)$ and deproteinized concentrated acid whey supernatant (DCAWS) $(\boldsymbol{\Delta}, \Delta)$. The dotted lines indicate the linear fit.

ported by different authors (Liang et al., 2004). Thirdly, Liang et al. (2004) reported typical slow nucleation kinetics (i.e., large induction time) and fast crystal growth for calcium lactate crystallization. Finally, the observed thickening seemed to be specific to lactic acid whey concentrates because no drastic increase in viscosity was observed in sweet whey concentrates or hydrochloric acid whey concentrates of comparable total solids.

\section{Influence of Calcium Lactate Supersaturation on Thickening}

As previously shown, thickening was consistent with calcium lactate precipitation and characterized in this study by induction time and torque amplitude $(\Delta F)$. The relationship between $\Delta F$, induction time and calcium lactate supersaturation were investigated, both in pure systems (i.e., supersaturated calcium lactate solution) and DCAWS. Temperature was kept at $20^{\circ} \mathrm{C}$ and $\mathrm{pH}$ was adjusted at 5.1. The calcium:lactate mass ratio was equal to $1: 10.3$ (molar ratio of 1:4.45). Assuming that almost all of the lactate was deprotonated at $\mathrm{pH} 5.1$ [pKa (lactic acid/lactate $)=3.9]$, it can be noted that lactate was in large excess with regard to the calcium for the formation of $\mathrm{Ca}$ (lactate) $)_{2} \cdot 5 \mathrm{H}_{2} \mathrm{O}$ crystals (molar ratio 1:2). Additionally, calcium $\mathrm{D} / \mathrm{L}$-lactate solubility was found to be equal to $0.158 \mathrm{~mol} / \mathrm{kg}$ (i.e., $0.656 \mathrm{~g}$ of $\mathrm{Ca} / 100 \mathrm{~g}$ of $\mathrm{H}_{2} \mathrm{O}$ at $20^{\circ} \mathrm{C}$ in water; Cao et al., 2001; Apelblat et al., 2005). Consequently, within the investigated range of concentrations, calcium lactate was supersaturated.

Torque Amplitude $(\Delta F)$ and Calcium Lactate Supersaturation. As illustrated in Figure 5, a linear 
relationship between $\Delta F$ and calcium content, within the investigated range, was found both in pure system and DCAWS. The high complexity of the system (e.g., high shear rate, complex shear flow, nondilute suspension, nonrandom spatial orientation of particles, elongated and flexible particles) did not allow us to predict the nature of the relationship between the viscosity or torque amplitude $(\Delta F)$ on the one hand, and the crystal mass, size, or shape on the other hand. However, because the dynamic viscosity of a particle suspension varied with the volume fraction of solid particles (Pabst et al., 2006), it is believed that $\Delta F$ was strongly related to the calcium lactate crystal volume fraction and hence to crystal mass in suspension. Consequently, $\Delta F$ would increase with calcium lactate content as increasing amounts of calcium lactate crystals were proportionally formed with an increase in supersaturation. The fact that $\Delta F$ varied with calcium lactate content above solubility had several consequences: 1) increasing TS of the concentrate led to proportional increase of calcium lactate content and consequently to higher increase in viscosity of the concentrate; 2 ) because calcium lactate solubility decreased with decreasing temperature (Cao et al., 2001; Apelblat et al., 2005), a decrease in temperature, at constant calcium lactate content, led to a greater increase in viscosity of the concentrate. The same consequences were reported by Hargrove et al. (1976) who observed that increasing the TS of whey concentrates above 40\% (wt/wt) markedly increased their viscosity and that decreasing temperature caused a drastic increase in the viscosity of highly concentrated whey (above $50 \% \mathrm{wt} / \mathrm{wt} \mathrm{TS}$ ). The temperature effect was further confirmed by Hargrove et al. (1976) who showed that whey concentrates of 50\% wt/wt TS held at $10^{\circ} \mathrm{C}$ were usually too viscous to pump to the dryer, whereas whey concentrates of the same TS content held between 25 and $42^{\circ} \mathrm{C}$ were pumped readily.

Induction Time and Calcium Lactate Supersaturation. In contrast to torque amplitude, the induction time varied inversely with calcium lactate supersaturation, both in the pure system and in DCAWS (Figure 5 ). These results are in good agreement with results of Liang et al. (2004) who reported, using spectrophotometry, an exponential decay relationship between calcium lactate supersaturation and induction time of precipitation conducted under static conditions, in pure supersaturated calcium lactate solution. The negative correlation between calcium lactate supersaturation and induction time was expected because induction time varies inversely with nucleation rate that is, according to classical homogeneous nucleation theory, strongly and positively correlated with supersaturation (Hartel, 2001).
Interestingly, for a given calcium content, induction time of calcium lactate precipitation was higher in DCAWS than in pure systems, as also observed by Liang et al. (2004) in cheese serum. Conversely, for a given calcium content, $\Delta F$ in DCAWS was lower than in pure systems. Hence, for a given calcium content, supersaturations of calcium lactate in DCAWS and in pure systems were thought to be different. Moreover, because supersaturation was defined as the difference between calcium lactate content and calcium lactate solubility, 2 assumptions could be made. First, there was higher solubility of calcium lactate in DCAWS than in pure systems. Because calcium-L-lactate was the most soluble isomer (Cao et al., 2001; Apelblat et al., 2005), a higher ratio of L- to D-lactate in DCAWS than in the racemic pure systems could result in higher solubility of calcium lactate in DCAWS and consequently, on lower supersaturation. The lower solubility and the increasing content of calcium-D-lactate due to racemization of lactic acid by nonstarter bacteria during cheese ripening were shown to explain the formation of calcium lactate crystals on the surface of Cheddar cheese (Johnson et al., 1990; Chou et al., 2003). Second, in DCAWS at $\mathrm{pH}$ 5.1, calcium ions were also complexed with other anions at the expense of the association with lactate ions, resulting in lower supersaturation. In other words, in DCAWS, the calculation of supersaturation based on total calcium content overestimated the effective supersaturation (as defined in this paper), provided this effective supersaturation took into account only the calcium involved in calcium lactate association equilibrium. This second assumption; that is, lower effective supersaturation of calcium lactate in DCAWS, was further emphasized in this study when $\mathrm{pH}$ and phosphate effects were investigated.

\section{Influence of $\mathrm{pH}$ on Thickening}

In DCAWS. The influence of $\mathrm{pH}$ of DCAWS (original $\mathrm{pH}=4.1$ ) both on $\Delta F$ and on induction time is shown in Figure 6. In the range of $\mathrm{pH}$ from 3.5 to $6.0, \Delta F$ first increased between $\mathrm{pH} 3.5$ and 4.6 and then decreased from $\mathrm{pH} 4.6$ to 6.0. Inversely, induction time decreased from $\mathrm{pH} 3.5$ to 4.6 and increased from $\mathrm{pH} 4.6$ to 6.0. Moreover, calcium phosphate precipitation occurred in DCAWS during runs at $\mathrm{pH} 5.5$ and $\mathrm{pH} 6.0$ (results not shown). This precipitation made the solution cloudy but did not induce an increase in flow resistance as observed for calcium lactate precipitation. Additionally, phosphate was shown to be highly concentrated in DCAWS (Table 1). From these results, $\mathrm{pH}$ and phosphate were likely to influence calcium lactate precipitation in DCAWS. Moreover, because the variations of torque amplitude $\Delta F$ and induction time were shown to depend 


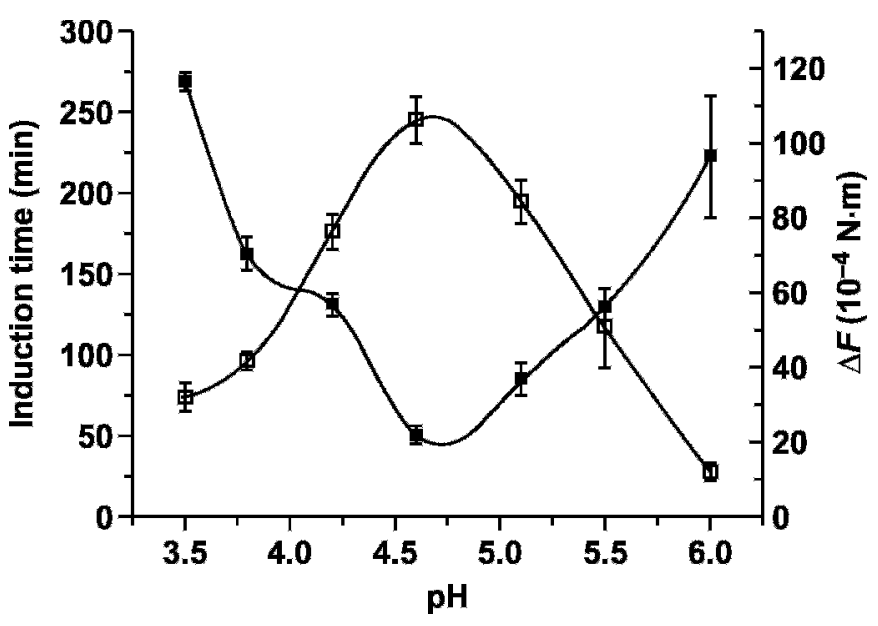

Figure 6. Induction time ( $\min , \mathbf{n})$ and respective torque amplitude $\left(\Delta F, 10^{-4} \mathrm{~N} \cdot \mathrm{m}, \square\right)$, as a function of $\mathrm{pH}$ during stirring of deproteinized concentrated acid whey supernatant (DCAWS) at $120 \mathrm{rad} / \mathrm{s}$ and $20^{\circ} \mathrm{C}$.

on variation of calcium lactate supersaturation (Figure 5), it is believed that $\mathrm{pH}$ and phosphate affected calcium lactate precipitation by modifying the effective calcium lactate supersaturation in DCAWS. This hypothesis was further confirmed in pure systems.

In Pure System. In the absence of phosphate, a drastic increase in $\Delta F$ was observed when the $\mathrm{pH}$ was raised from 3.5 to 5.1 (Table 2). No further significant change in $\Delta F$ was detected by further increase in $\mathrm{pH}$ to 6.1 . Because $\Delta F$ was positively correlated with effective calcium lactate supersaturation (Figure 5), these results are in good agreement with those of Rothbassell and Clydesdale (1992) who dissolved more calcium lactate pentahydrate powder in water at $\mathrm{pH} 2.0$ than at $\mathrm{pH}$ 7.0, and those of Kubantseva et al. (2004) who did not show variation in calcium lactate solubility from $\mathrm{pH}$ 5.0 to $\mathrm{pH} 6.5$ in water. From $\mathrm{pH} 3.5$ to 5.1, the evolution of $\Delta F$ can be reasonably ascribed to lactic acid-lactate equilibrium. Lactate concentration was low enough, with regard to the calcium concentration, to be the limiting factor for the association between lactate and calcium ions (i.e., $2 \mathrm{~mol}$ of lactate per mol of calcium) and hence to limit the effective calcium lactate supersatura-

Table 2. Torque amplitude $\left(\Delta F, 10^{-4} \mathrm{~N} \cdot \mathrm{m}\right)$ of calcium lactate supersaturated solutions $\left([\mathrm{Ca}]=1.34 \mathrm{~g} / 100 \mathrm{~g}\right.$ of $\left.\mathrm{H}_{2} \mathrm{O}\right)$, at different $\mathrm{pH}$, during stirring at $120 \mathrm{rad} / \mathrm{s}$ and $20^{\circ} \mathrm{C}$, with and without phosphate ions

\begin{tabular}{lrr}
\hline & \multicolumn{2}{c}{$\begin{array}{c}\text { Phosphate concentration } \\
\left(\mathrm{g} / 100 \mathrm{~g} \text { of } \mathrm{H}_{2} \mathrm{O}\right)\end{array}$} \\
\cline { 2 - 3 } $\mathrm{pH}$ & \multicolumn{1}{c}{1.53} \\
\hline 3.5 & $5.0 \pm 1.5$ & $4.4 \pm 0.5$ \\
5.1 & $60.4 \pm 0.9$ & $40.2 \pm 4.1$ \\
6.1 & $64.7 \pm 2.4$ & $25.0 \pm 4.7$ \\
\hline
\end{tabular}

Table 3. Association constants of calcium with various anions (L/ mol) as calculated at low ionic strength by Holt et al. (1981)

\begin{tabular}{lc}
\hline Anions & $\begin{array}{l}\text { Association constant } \\
\text { with } \mathrm{Ca}^{2+}(\mathrm{L} / \mathrm{mol})\end{array}$ \\
\hline $\mathrm{RCOO}^{-}$(lactate) & 15 \\
$\mathrm{H}_{2} \mathrm{PO}_{4}^{-}$ & 11 \\
$\mathrm{HPO}_{4}{ }^{2-}$ & 642 \\
$\mathrm{PO}_{4}{ }^{3-}$ & $2.88 \times 10^{6}$ \\
\hline
\end{tabular}

tion. As the latter decreased with decreasing $\mathrm{pH}$ from 5.1 to 3.5, the amount of calcium lactate crystals formed during precipitation would decrease and consequently $\Delta F$ decreased. From $\mathrm{pH}$ 5.1, lactate concentration was high and the calcium concentration became the limiting factor for the association. Because total calcium content was constant and $\mathrm{NaCl}$ does not affect the effective calcium lactate supersaturation (Kubantseva et al., 2004 ), it is likely that $\Delta F$ did not change with $\mathrm{pH}$ from 5.1 to 6.1 because of constant effective calcium lactate supersaturation in this $\mathrm{pH}$ range.

In the presence of phosphate (Table 2 ; mass ratio of $\mathrm{Ca}: \mathrm{PO}_{4}=1: 1.14$, molar ratio of $\left.\mathrm{Ca}: \mathrm{PO}_{4}=1: 0.5\right)$ at $\mathrm{pH}$ $5.1, \Delta F$ was significantly lower than in the absence of phosphate. As observed without phosphate ions, $\Delta F$ increased with $\mathrm{pH}$ from 3.5 to 5.1. However, contrary to what occurred without phosphate, $\Delta F$ significantly decreased from 5.1 to 6.1 , exhibiting the same behavior as observed in DCAWS (Figure 6). Additionally, calcium phosphate precipitation instantaneously occurred at pH 6.1, as observed by turbidimetry (results not shown). These results suggested that the presence of phosphate was the cause of the lower value of $\Delta F$, for a given calcium content, in DCAWS than in the pure system at $\mathrm{pH} 5.1$ (Figure 5), confirming the second assumption proposed earlier. These results also suggested that phosphate ions were involved in the $\Delta F$ decrease observed in the pure system from $\mathrm{pH}$ 5.1, and in DCAWS from $\mathrm{pH}$ 4.6. The relative association constant values between calcium and anions published by Holt et al. (1981) are summarized in Table 3. Because association constants between calcium ions and deprotonated phosphate ions were much higher than between calcium and protonated phosphate ions, it is thought that, with increasing $\mathrm{pH}$, calcium ions were increasingly associated with phosphate ions at the expense of the association with lactate ions. Such competition for the chelation of calcium between lactate and phosphate ions led to a reduced effective calcium lactate supersaturation and consequently to a reduced $\Delta F$.

\section{CONCLUSIONS}

The experimental procedure developed in this study allowed the induction of whey thickening by stirring, 
under controlled conditions of temperature and agitation, and the quantification of thickening by torque measurement in real time. Drastic increases in flow resistance of the lactic acid whey concentrates (also called thickening at industrial scale) were shown to be the result of calcium lactate precipitation. The typical filament-like shape of calcium lactate crystals explained the sharp increase in viscosity of the suspension in contrast with precipitation of isometric crystals in comparable volume fractions. Thickening of lactic acid whey concentrates showed a large dependence on calcium and lactate contents, $\mathrm{pH}$, and the presence of phosphate, all of which are believed to affect, directly or indirectly, calcium lactate supersaturation.

\section{REFERENCES}

Aoki, T. Z., T. Iwashita, T. Hotanii, M. Shiokawa, S. Ohki, and H. Iwasaki. 2002. Increase in the viscosity of concentrated skim milk during storage at low temperature. Milchwissenschaft 57:532535 .

Apelblat, A., E. Manzurola, J. van Krieken, and G. L. Nanninga. 2005. Solubilities and vapour pressures of water over saturated solutions of magnesium-L-lactate, calcium-L-lactate, zinc-L-lactate, ferrous-L-lactate and aluminum-L-lactate. Fluid Phase Equilib. 236:162-168.

Ausias, G., X. J. Fan, and R. I. Tanner. 2006. Direct simulation for concentrated fibre suspensions in transient and steady state shear flows. J. Non-Newt. Fluid Mech. 135:46-57.

Bienvenue, A., R. Jimenez-Flores, and H. Singh. 2003. Rheological properties of concentrated skim milk: Influence of heat treatment and genetic variants on the changes in viscosity during storage. J. Agric. Food Chem. 51:6488-6494.

Brule, G., J. L. Maubois, and J. Fauquant. 1974. Contents of mineral elements in products from ultrafiltered milk. Lait 54:600-615.

Buma, T. 1980. Viscosity and density of concentrated lactose solutions and of concentrated cheese whey. Neth. Milk Dairy J. 34:65-68.

Cao, X., H. J. Lee, H. S. Yun, and Y. M. Koo. 2001. Solubilities of calcium and zinc lactate in water and water-ethanol mixture. Korean J. Chem. Eng. 18:133-135.

Chou, Y. E., C. G. Edwards, L. O. Luedecke, M. P. Bates, and S. Clark. 2003. Nonstarter lactic acid bacteria and aging temperature affect calcium lactate crystallization in Cheddar cheese. J. Dairy Sci. 86:2516-2524.

Fan, X. J., N. Phan-Thien, and R. Zheng. 1998. A direct simulation of fibre suspensions. J. Non-Newt. Fluid Mech. 74:113-135.

Fauquant, J., J. L. Maubois, and A. Pierre. 1988. Microfiltration of milk using a mineral membrane. Tech. Lait. Marketing 1028:21-23.
Gaucheron, F., Y. Graet, M. Piot, and E. Boyaval. 1996. Determination of anions of milk by ion chromatography. Lait 76:473-483.

Hargrove, R., F. McDonough, and J. Alford. 1974. Whey fraction converted into animal feed - without drying. Food Eng. 46:77-78.

Hargrove, R., F. McDonough, D. LaCroix, and J. Alford. 1976. Production and properties of deproteinized whey powders. J. Dairy Sci. 59:25-33.

Hartel, R. W. 2001. Nucleation. Pages 145-188 in Crystallization in Foods. Aspen Publishers, Gaithersburg, MD.

Holt, C., D. G. Dalgleish, and R. Jenness. 1981. Calculation of the ion equilibria in milk diffusate and comparison with experiment. Anal. Biochem. 113:154-163.

Jensen, G., and J. Oxlund. 1988. Concentration and drying of whey and permeate. Int. Dairy Fed. Bull. 233:4-20.

Johnson, M., B. Riesterer, and N. Olson. 1990. Influence of nonstarter bacteria on calcium lactate crystallization on the surface of Cheddar cheese. J. Dairy Sci. 73:1145-1149.

Kubantseva, N., R. W. Hartel, and P. A. Swearingen. 2004. Factors affecting solubility of calcium lactate in aqueous solutions. J. Dairy Sci. 87:863-867.

Liang, B., N. Kubantseva, and R. W. Hartel. 2004. Solubility and crystallization kinetics of calcium lactate in aqueous systems. Abstr. 444 in Proc. Int. Congr. Eng. Food, Montpellier, France. Société de Chimie Industrielle, Paris, France.

Marti, I., O. Hofler, P. Fischer, and E. J. Windhab. 2005. Rheology of concentrated suspensions containing mixtures of spheres and fibres. Rheologica Acta 44:502-512.

Mikelsone, A. 1984. Changes in viscosity of ammoniated whey concentrate after neutralization. Trudy, Latviiskaya Ordena Trudovogo Krasnogo Znameni Sel'skokhozyaistvennaya Akademiya 218:44-48.

Mimouni, A., P. Schuck, and S. Bouhallab. 2005. Kinetics of lactose crystallization and crystal size as monitored by refractometry and laser light scattering: Effect of proteins. Lait 85:253-260.

Noda, K., M. Endo, and T. Takahashi. 1976. Physico-chemical changes in sweetened condensed milk during storage. Jpn. J. Zootech. Sci. [Nihon Chikusan Gakkai-ho] 47:719-724.

Pabst, W., E. Gregorova, and C. Berthold. 2006. Particle shape and suspension rheology of short-fiber systems. J. Eur. Ceram. Soc. 26:149-160.

Petrie, C. J. S. 1999. The rheology of fibre suspensions. J. Non-Newt. Fluid Mech. 87:369-402.

Rothbassell, H. A., and F. M. Clydesdale. 1992. In vitro solubility characteristics of 6 calcium salts. J. Food Prot. 55:1003-1005.

Schuck, P., A. Davenel, F. Mariette, V. Briard, S. Mejean, and M. Piot. 2002. Rehydration of casein powders: Effects of added mineral salts and salt addition methods on water transfer. Int. Dairy J. 12:51-57.

Schuck, P., S. Mejean, A. Dolivet, E. Beaucher, and M. H. Famelart. 2005. Pump amperage: A new method for monitoring viscosity of dairy concentrates before spray drying. Lait 85:361-367.

Snoeren, T., J. Brinkhuis, A. Damman, and H. Klok. 1984. Viscosity and age-thickening of skim-milk concentrate. Neth. Milk Dairy J. $38: 43-53$. 